Journal of Sustainable Development of Transport and Logistics

journal home page: https://jsdtl.sciview.net

Jayarathna, N., Lanel, J., \& Juman, Z. A. M. S. (2020). Five years of multi-depot vehicle routing problems. Journal of Sustainable Development of Transport and Logistics, 5(2), 109-123. doi:10.14254/jsdtl.2020.5-2.10.

\title{
Five years of multi-depot vehicle routing problems
}

\author{
Nuwan Jayarathna $*(\mathbb{D}$, Jayantha Lanel $* *(\mathbb{D}$, Z.A.M.S. Juman $* * * \mathbb{D}$ \\ * Colombo International Nautical and Engineering College, Sri Lanka \\ nuwan@cinec.edu \\ ** University of Sri Jayewardenepura, Sri Lanka \\ ghjlanel@sjp.ac.lk \\ *** University of Peradeniya, Sri Lanka \\ jumanabdeen@yahoo.com
}

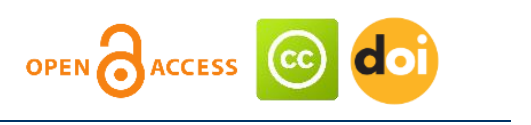

Article history:

Received: August 18, 2020

1st Revision: September 16, 2020

Accepted: November 07, 2020

\section{DOI:}

10.14254/jsdtl.2020.5-2.10

\begin{abstract}
With vast range of applications in real life situations, the Vehicle Routing Problems (VRPs) have been the subject of countless studies since the late 1950s. However, a more realistic version of the classical VRP, where the distribution of goods is done from several depots is the Multi-Depot Vehicle Routing Problem (MDVRP), which has been the central attraction of recent researches. The objective of this problem is to find the routes for vehicles to serve all the customers at a minimal cost in terms of the number of routes and the total distance travelled without violating the capacity and travel time constraints of the vehicles, and it is handled with a variety of assumptions and constraints in the existing literature. This survey reviews the current status of the MDVRP and discuss the future direction regarding this problem.
\end{abstract}

Keywords: multi-depot vehicle routing problem, exact methods, heuristic, meta-heuristic.

\section{Introduction}

The Vehicle Routing Problem (VRP) can be identified as a generalization of the Travelling Salesman Problem. It is the issue of figuring out the lowest cost delivery directions or paths from a depot to a set of geographically dispersed clients, with a focus to crosswise limitations (Jayarathna et al., 2019). Despite the many studies conducted based on the VRP, it does not present very realistic applications (see (Modeling of an Optimal Outbound Logistics System (A Contemporary Review Study on effects of Vehicle Routing, Facility Location and Locational Routing Problems) for a recent contemporary review study on VRPs). Hence, at present more attention is focused on a variant of the VRP which offers more realistic scenario known as the MDVRP.

Corresponding author: Nuwan Jayarathna

E-mail: nuwan@cinec.edu

This open access article is distributed under a Creative Commons Attribution (CC-BY) 4.0 license. 


\subsection{Introduction to Multi-Depot Vehicle Routing Problems}

Figure 1.1: MDVRP Plan

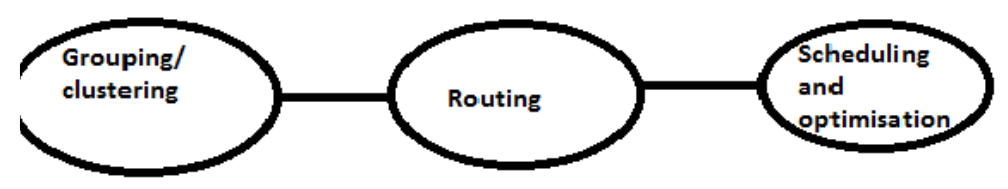

In general, the objective of the MDVRP is to minimize the total delivery distance or time spent in serving all customers. Lesser the delivery time, higher the customer satisfaction. Fewer vehicles mean that the total operation cost is less, thus the objective can also be minimizing the number of vehicles. Though there may be several objectives, the aim of MDVRP is to increase the efficiency of delivery.

The Multi-Depot Vehicle Routing Problem (MDVRP) (Pardalos \& Coleman, 2009) is a generalization of the Single-Depot Vehicle Routing Problem (SDVRP) in which vehicle(s) start from multiple depots and return to their depots of origin at the end of their assigned tours. The traditional objective in MDVRP is to minimize the sum of all tour lengths, and existing literature handles this problem with a variety of assumptions and constraints.

Multi Depot Vehicle Routing Problem (MDVRP) implicates number of depots instead of only one. In the traditional approach it was considered that each vehicle is assigned same number of nodes, but in MDVRP same number of vehicles is assigned to each depot. In the former case i.e in VRP the results were poor thus this technique is accepted as this gives better results than VRP. In most of the real-life VRPs, demands at the customer nodes vary due to various factors, such as location and temporal seasonal factors. A network routing topology generated by solving min-max MDVRP results in a set of daisy-chain network configurations that minimize the maximum latency between a server and client. This can be advantageous in situations in which the server-client connection cost is high but the clientclient connection cost is low. Vehicles should start from the depot and then return back to the depot after serving an ample amount of customers. Every customer has a demand which varies stochastically. Vehicles are assigned to the customers and one customer is served by only one vehicle. There are few considerations which should be kept in mind while implementing MDVRP.

1) Vehicle should start and end its route at the depot.

2) A customer is visited exactly once by the vehicle in each cluster.

3) Total cost to traverse the customers is minimized.

In traditional MDVRP attempt was made to reduce the total distance travelled whereas in this case attempt is being made to reduce the maximum distance travelled by the vehicle. This is done by making clusters based upon the distance of cluster from the depot. Number of routes should be equal to or less than the number of depots. More number of routes increase the number of vehicles required thus reducing the quality of solution. Customers are assigned to different routes. The distance is computed according to the following rule:

- If $D\left(c_{i}, A\right)<D\left(c_{i}, B\right)$, then customer $c_{i}$ is assigned to $\operatorname{depot} A$

- If $D\left(c_{i}, A\right)>D\left(c_{i}, B\right)$, then customer $c_{i}$ is assigned to depot $B$

- If $\mathrm{D}\left(\mathrm{c}_{\mathrm{i}}, \mathrm{A}\right)=\mathrm{D}\left(\mathrm{c}_{\mathrm{i}}, \mathrm{B}\right)$, then customer $\mathrm{c}_{\mathrm{i}}$ is assigned to a depot chosen arbitrarily between $\mathrm{A}$ and $\mathrm{B}$.

Figure 1.2: Random distribution of cities and depots

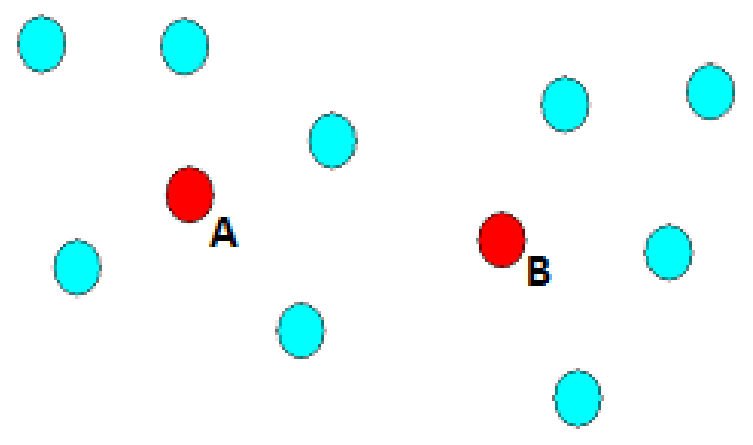


Figure 1.3: Assignment of cities to depots by computing distance
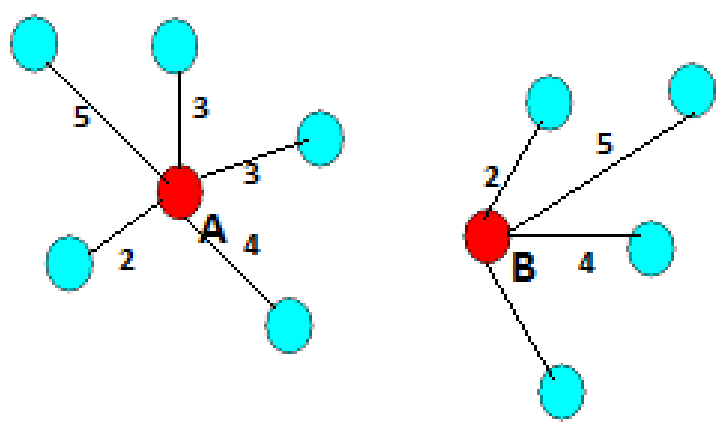

Figure 1.4: Routes formed by taking minimum distance as first choice
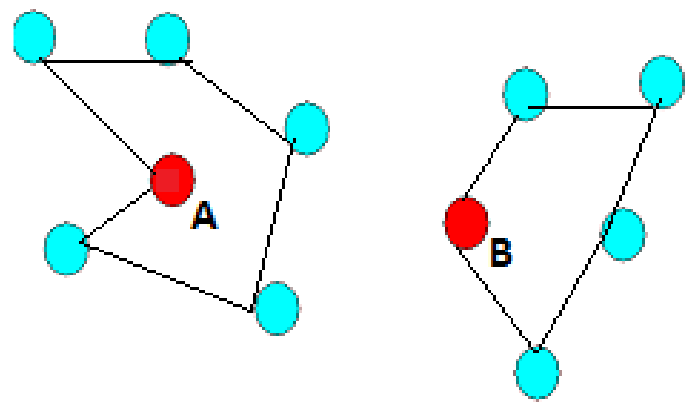

In all the above figures MDVRP is shown and the goal is to visit all the cities by covering minimum distance. Here we cover it by calculating the distances from depots to cities.

\section{Nearest neighbor function}

1) Each customer/city is assigned to the nearest depot.

2) Routes are made by traversing the vehicles over the cities (initial solution is made).

3) Local improvement method is applied to the routes initially formed in order to get better results.

In the above diagrams this method is applied to find routes which occur at minimum distance from one another. Each depot serves a set of customers which are given to this depot based upon the distance from the depot. Here the numbers of vehicles are generally equal to the number of depots. The length of tour length generated by this method is comparable to the traditional approaches. This method is capable of processing thousands of customers in seconds, along with the property of a scalability which is becoming increasingly important as networks expand in size. For example, consider a network model in which depots represent servers and customers represent clients. This can be advantageous in situations in which the server-client connection cost is high but the client-client connection cost is low.

The previous publication (Montoya-Torres et al., 2015) has presented a state-of-the-art survey on the MDVRP, reviewing the work published between the years 1988 and 2014. In this paper, we present a comprehensive review of the literature since 2015 including several significant publications before 2015. Moreover, we discuss the possible future orientations of the MDVRP in association with the suggestions presented in the existing literature.

The MDVRP can be single objective or multi-objective. The solution of the MDVRP could be obtained using an exact, heuristic or meta-heuristic method. The section 2 of the paper includes a review on the exact methods and in section 3 we discuss the heuristic and meta-heuristic techniques used by various researchers focusing on different variants of the MDVRP. 


\section{Exact methods}

The exact methods are the methods designed to solve a problem to optimality. However, they are not very ideal for NP-hard problems unless the size of the problem is considerably small. Wide range of researches have been conducted introducing different exact methods for MDVRPs and an overview of the related literature is discussed in this section.

An exact algorithm with a stronger lower bound for the vehicle flow formulation than those in the previous literature was presented in (Contardo \& Martinelli, 2014). The authors have prepared the MDVRP using a vehicle flow and a set partitioning formulation and most stupendously, have solved 14 open instances found in the relevant past literature. The future studies in this direction could be focused on improving the cutting planes in the cutting planes method employed in the solution process and generalization of k-CEC and SDC cuts which are two families of valid inequalities that can even be utilized in other classes of VRPs and multi-period VRPs (Contardo \& Martinelli, 2014).

In (Yücenur \& Demirel, 2011) a novel geometric shape based genetic clustering algorithm to solve MDVRP was proposed. The algorithm have proved better performance in terms of the distance between each customer and each depot in clusters.

A MDVRP for a heterogeneous vehicle fleet was studied in (Salhi et al., 2014) by setting lower as well as upper bounds. The solution of the problem was accomplished using an efficient variable neighbourhood search integrating several novel features such as a preprocessing scheme for identification of borderline customers, a mechanism that aggregates and disaggregates routes between depots, and a neighbourhood reduction test that saves nearly $80 \%$ of the CPU time, especially on the large instances (Salhi et al., 2014). This result can be thought to be very remarkable since it has produced 23 new best results when tested on 26 previously published data instances in the existing literature.

Coevolutionary algorithms are a type of evolutionary algorithms arising in the process of simultaneous evolution related to two or more species(De Oliveira et al., 2016). Oliveira et al. in (De Oliveira et al., 2016) have introduced a cooperative coevolutionary algorithm which has the capacity to minimize MDVRP that can be regarded as the first ever study involving such an algorithm. The study also resulted in advantages in parallel evolution strategy environments since the authors have decomposed the MDVRP, making each sub problem in to a single depot VRP in devising the solution.

Kachitvichyanukul, Sombuntham and Kunnapapdeelert in (Kachitvichyanukul et al., 2015) developed two solution representations for solving the generalized MDVRP with multiple pickup and delivery requests, by formulating the mathematical model as an extension of Ropke and Pisinger (Ropke \& Pisinger, 2006).

A generalization of the Capacitated VRP, Multi-Depot Open VRP was addressed by (Soto et al., 2017) through the development of a Multiple Neighbourhood Search in hybridization with a Tabu Search strategy and then secondly using an ejection chain composed with the capacity to handle several neighbourhoods.

The presence of multi-compartments for a MDVRP create better integration in the routing process and hence offer a more efficient solution. Nevertheless the advantages available, the multi-compartment variant of the MDVRP has attacted scarce attention in the extensive literature up to date. In 2018, (Alinaghian \& Shokouhi, 2018) have developed a hybrid algorithm involving significantly large neighbourhood and variable neighbourhood search to solve large scale instances based on a set of assumptions (Alinaghian \& Shokouhi, 2018) such as:

- Vehicles have multiple compartments

- Each compartment is dedicated to one type of product

- Each customer can be served by multiple vehicles

- Each vehicle is assigned to one depot

- Demands of all customers must be fully met

- Each vehicle starts its tour from a depot and in the end returns to the same depot etc.

Despite the records of several researches on multi-compartment VRP and MDVRP, (Alinaghian \& Shokouhi, 2018) can be regarded as the first research conducted on a multi-depot multi-compartment VRP. Moreover, it is remarkable that a solution was proposed to minimize the number of vehicles and then again to minimize the number of total traversed routes.

The cost minimization in distribution is a requirement with high demand in devising a vehicle route plan in real life situations and hence is widely studied (Ganepola et al., 2018). Shared depot 
resources facilitate the route of a vehicle to start from a depot and end at any one of the depots sets while reducing the delivery distance and fuel consumption. In (J. Li et al., 2018), the authors have conducted a benefit analysis about the shared depot resources for a MDVRP and concluded that the characteristics depot-customer geographic distribution, maximum route distance and the number of depots are the factors that have the most significant influence on the relative performance in the presence of shared resources.

(Tohidifard et al., 2018) have proposed a novel robust mathematical model for a MDVRP with time windows to be used by home health care firms. This real life problem was stated with several assumptions to formulate the mathematical model and was solved using a genetic algorithm and particle swarm optimization. The presence of ordered and on time medical services for patients in their locations have many advantages and the solution presented in (Tohidifard et al., 2018) has optimized the satisfaction of patients while minimizing the distance and time taken to travel, the number of vehicles and the transportation costs in a patient's hardtime windows.

The Mathematical formulation of the model is as follows.

$$
\begin{aligned}
& \operatorname{Min} \sum_{i=1}^{n} \sum_{j=n+1}^{m+n+1} \sum_{k=1}^{K} c_{i j} x_{i j k}+\sum_{i=n+1}^{m+n+1} \sum_{j=n+1}^{m+n+1} \sum_{k=1}^{K} c_{i j} x_{i j k}+\sum_{j=1}^{n} g_{i} y_{i} \\
& u_{i}-u_{j}+q_{k} x_{i j k} \leq q_{k}-d_{1, j} \quad \forall k \in K \\
& \sum_{j \in N} \sum_{k=1}^{k} x_{i j k}=2 \\
& \sum_{j \in N} \sum_{k=1}^{k} x_{i j k}=1 \\
& \sum_{i=1}^{n+m+1} x_{i h k}-\sum_{j=1}^{n+m+1} x_{h j k}=0 \\
& \sum^{n} \sum^{n+m+1} \quad \forall k \in K \\
& \sum_{\substack{j=1 \\
n+m+1}} x_{i j k}=1 \quad \forall k \in K \\
& \sum_{i=n+1} x_{i(n+m+1) k}=1 \\
& s_{i k}+w_{i k}+t_{i j}-M\left(1-x_{i j k}\right) \leq s_{j k} \quad \forall i, j \in N \\
& \begin{array}{ll}
e_{i} \leq s_{i k} \leq l_{i} & \forall k \in K \\
& \forall i \in P P
\end{array}
\end{aligned}
$$

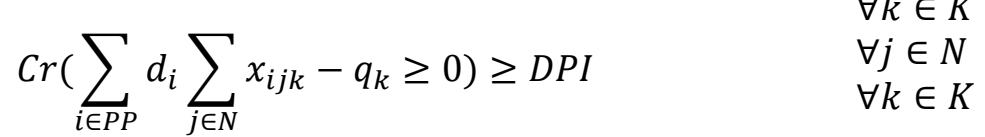

$$
\begin{aligned}
& \sum_{k=1}^{k} \sum_{j=n+1}^{m+n+1} \sum_{i=1}^{n} x_{j i k}=p \\
& \sum_{i=1}^{n} x_{i j k} \leq 1 \\
& \sum_{i=1}^{n} \sum_{j=1}^{n} x_{i j k}=0 \\
& \sum_{i \in N} \sum_{k=1}^{k} x_{j i k} \leq M y_{i} \\
& \begin{aligned}
x_{i j k} \in\{0,1\} ; y_{j \in d} \in\{0,1\} & \forall i, j \in N \\
& \forall k \in K
\end{aligned}
\end{aligned}
$$




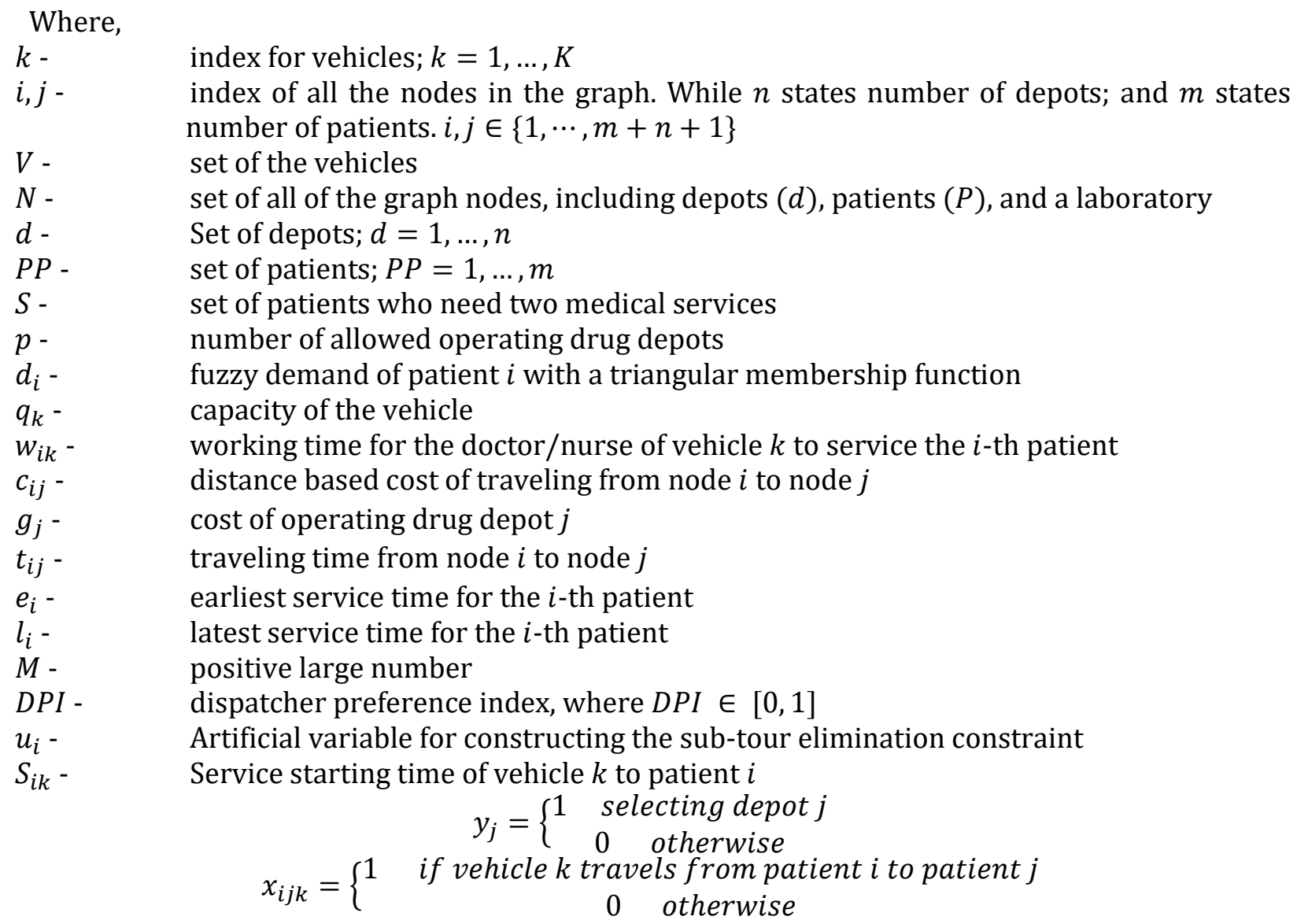

The authors have also suggested future directions of studying such as using other methods like robust programming, robust probabilistic programming or stochastic programming in dealing with uncertain data involved. Focusing on other objective functions such as maximizing patient satisfaction is another interesting direction.

In (Seyyedhasani \& Dvorak, 2018), the authors have developed a method which allows dynamic recalculation of routes involving a dynamic environment in agricultural work. There a combination of Dynamic VRP and MDVRP was used and the proposed solution illustrated the possibility to update field routes for a fleet of vehicles during agricultural field operations very well.

The VRPs faced by different organizations or companies are usually distinguished based on the additional constraints related to various operational aspects such as environmental regulations, labour laws, politics, contracts with customers, markets etc. Such VRPs are generally identified as Rich Vehicle Routing Problems (RVRP).

In 2019, Kramer, Cordeau and Lori (Kramer et al., 2019) proposed a solution to a RVRP having multiple depots using a multi-start iterated local search algorithm. The algorithms was based on a real life problem faced by a logistics provider who delivers pharmaceutical products to healthcare facilities in Tucay and analyzed with respect to having heterogeneous fleet of vehicles, flexible time windows, periodic demands, incompatibilities between vehicles and customers, a maximum duration for the routes and a maximum number of customers per route.

The solutions presented in (E. Osaba et al., 2017) and (Eneko Osaba et al., 2019) have addressed the Multi-Depot RVRP for real world problems on a drug distribution problem faced due to a newspaper distribution problem with recycling policy and a pharmacological waste collection in 2017 and 2019 respectively, which were the very first times that such two problems were addressed in the history.

Following table includes a summary of the researches that have introduced exact solution techniques to solve MDVRP, the variety of constraints considered, exact method of solution presented, and the real-life situation considered in formulation of the problem.

And iterated local search algorithm to address Multi-Depot Open VRP is presented in (Brandão, 2020). The algorithm operates by recalling the moves performed during the local search. There 
historical search information is utilized to define the moves executed inside the perturbation procedures.

In (Zhen et al., 2020), the authors have investigated the MDVRP with respect to the practical scenario in a last mile distribution operation. The authors express the design of a set of trips for the fleet of vehicles where there are several depots for minimizing the total travelling time. As the solution, a mixed integer programming model is solved using a hybrid particle swarm optimization algorithm and a hybrid genetic algorithm.

Table 1: Summary of MDVRPs presenting exact methods of solution from 2015-2020

\begin{tabular}{|c|c|c|c|c|}
\hline $\mathbf{S} / \mathbf{N}$ & Authors & Nature of constraint & $\begin{array}{l}\text { Method of } \\
\text { solution }\end{array}$ & Real-life application \\
\hline 1 & $\begin{array}{l}\text { Contardo and Martinelli } \\
\text { (Contardo \& Martinelli, 2014) }\end{array}$ & $\begin{array}{l}\text { Total transportation } \\
\text { cost }\end{array}$ & $\begin{array}{ll}\text { Cutting } & \text { plane } \\
\text { method } & \end{array}$ & Transportation network \\
\hline 2 & $\begin{array}{l}\text { Yücenur and Demirel } \\
\text { (Yücenur \& Demirel, 2011) }\end{array}$ & $\begin{array}{l}\text { Total traveled distance } \\
\text { between each depot } \\
\text { and the customers } \\
\text { which are assigned to } \\
\text { the depot. }\end{array}$ & $\begin{array}{lr}\text { Geometric } & \text { shape } \\
\text { based } & \text { genetic } \\
\text { clustering } & \\
\text { technique } & \end{array}$ & Transportation network \\
\hline 3 & $\begin{array}{l}\text { Salhi, Imran and Wassan } \\
\text { (Salhi et al., 2014) }\end{array}$ & Total distribution cost & $\begin{array}{l}\text { Variable } \\
\text { neighbourhood } \\
\text { search }\end{array}$ & Transportation network \\
\hline 4 & $\begin{array}{l}\text { Oliveira et al. (De Oliveira et } \\
\text { al., 2016) }\end{array}$ & $\begin{array}{l}\text { Total transportation } \\
\text { cost }\end{array}$ & $\begin{array}{l}\text { Problem } \\
\text { decomposition } \\
\text { approach and } \\
\text { solution } \\
\text { cooperative } \\
\text { coevolutionary } \\
\text { algorithm }\end{array}$ & Transportation network \\
\hline 5 & $\begin{array}{l}\text { Kachitvichyanukul, } \\
\text { Sombuntham and } \\
\text { Kunnapapdeelert } \\
\text { (Kachitvichyanukul et al., } \\
2015 \text { ) }\end{array}$ & $\begin{array}{l}\text { Variety of constraints } \\
\text { to meet multiple } \\
\text { pickup and delivery } \\
\text { requests such as total } \\
\text { transportation cost, } \\
\text { number of vehicles, } \\
\text { demand etc. }\end{array}$ & $\begin{array}{l}\text { Particle swarm } \\
\text { optimization with } \\
\text { solution } \\
\text { representations, } \\
\text { SD2 and SD3 }\end{array}$ & Transportation network \\
\hline 6 & Soto et al. (Soto et al., 2017) & $\begin{array}{l}\text { Minimize the total } \\
\text { traveling length } \\
\text { satisfying the following } \\
\text { constraints: }\end{array}$ & $\begin{array}{l}\text { Tabu } \\
\text { strategy }\end{array}$ & Transportation network \\
\hline & & $\begin{array}{l}\text { - each route } \\
\text { starts at any depot } \\
\text { and finishes at the } \\
\text { last visited } \\
\text { customer, } \\
\text { - each customer must } \\
\text { be visited by exactly } \\
\text { one vehicle, } \\
\text { - the total demand of } \\
\text { the customers on the } \\
\text { route of any vehicle } \\
\text { cannot } \\
\text { exceed its capacity, } \\
\text { - the total length of } \\
\text { each vehicle route } \\
\text { must not exceed the } \\
\text { length } \\
\text { limit. }\end{array}$ & & \\
\hline 7 & $\begin{array}{lll}\text { Alinaghian } & \& & \text { Shokouhi } \\
\text { (Alinaghian } & \& & \text { Shokouhi, } \\
\text { 2018) } & & \end{array}$ & $\begin{array}{l}\text { Minimization of the } \\
\text { number of vehicles and } \\
\text { minimization of the } \\
\text { total traversed routes. }\end{array}$ & $\begin{array}{l}\text { Adaptive large } \\
\text { neighborhood } \\
\text { search and variable } \\
\text { neighborhood } \\
\text { search }\end{array}$ & Transportation network \\
\hline
\end{tabular}




\begin{tabular}{|c|c|c|c|c|}
\hline 8 & $\begin{array}{l}\text { Ganepola et al. (Ganepola et } \\
\text { al., 2018) }\end{array}$ & $\begin{array}{lrr}\text { Minimization of } & \text { cost } \\
\text { associated } & & \text { in } \\
\text { distribution } & & \end{array}$ & $\begin{array}{l}\text { Gravity model and } \\
\text { determination of a } \\
\text { Hamiltonian cycle } \\
\text { using Lingo } \\
\text { software }\end{array}$ & $\begin{array}{l}\text { Distribution of bottles and } \\
\text { cans from Lion Brewery } \\
\text { Ceylon PLC., Biyagama. }\end{array}$ \\
\hline 9 & Li et al. (J. Li et al., 2018) & $\begin{array}{l}\text { Minimizing delivery } \\
\text { distance and fuel } \\
\text { consumption }\end{array}$ & $\begin{array}{lr}\text { Hybrid } & \text { genetic } \\
\text { algorithm } & \text { with } \\
\text { daptive } & \text { local } \\
\text { search } & \end{array}$ & Transportation network \\
\hline 10 & $\begin{array}{l}\text { Tohidifard et al. (Tohidifard et } \\
\text { al., 2018) }\end{array}$ & $\begin{array}{l}\text { Minimizing the } \\
\text { distance and time of } \\
\text { the travelling tour, the } \\
\text { number of vehicles and } \\
\text { the transportation } \\
\text { cost. }\end{array}$ & $\begin{array}{l}\text { Genetic algorithm } \\
\text { and Particle Swarm } \\
\text { Optimization }\end{array}$ & $\begin{array}{l}\text { MDVRP with time } \\
\text { windows for home health } \\
\text { care firms }\end{array}$ \\
\hline 11 & $\begin{array}{l}\text { Seyyedhasani } \\
\text { Dvorak(Seyyedhasani } \\
\text { Dvorak, 2018) }\end{array}$ & $\begin{array}{l}\text { Reallocation and } \\
\text { rescheduling of the } \\
\text { paths that create the } \\
\text { in-field route for each } \\
\text { vehicle }\end{array}$ & $\begin{array}{ll}\text { Dynamic } & \text { MDVRP } \\
\text { approach } & \end{array}$ & Agricultural field work \\
\hline 12 & $\begin{array}{l}\text { Cordeau \& Lori (Kramer et al., } \\
\text { 2019) }\end{array}$ & $\begin{array}{l}\text { Maximum duration for } \\
\text { the routes and a } \\
\text { maximum number of } \\
\text { customers per route }\end{array}$ & $\begin{array}{l}\text { Multi-start iterated } \\
\text { local } \\
\text { approach }\end{array}$ & $\begin{array}{l}\text { Deliver pharmaceutical } \\
\text { products to } \\
\text { healthcare facilities in } \\
\text { Tuscany }\end{array}$ \\
\hline 13 & $\begin{array}{l}\text { Osaba et al. (E. Osaba et al., } \\
\text { 2017) }\end{array}$ & Minimize the total cost & $\begin{array}{l}\text { Discrete } \\
\text { algorithm }\end{array}$ & $\begin{array}{l}\text { Newspaper distribution } \\
\text { with recycling policy }\end{array}$ \\
\hline 14 & $\begin{array}{l}\text { Osaba et al. (Eneko Osaba et } \\
\text { al., 2019) }\end{array}$ & $\begin{array}{l}\text { Minimize all costs } \\
\text { associated with the } \\
\text { routes }\end{array}$ & $\begin{array}{l}\text { Discrete } \\
\text { Improved } \\
\text { Algorithm }\end{array}$ & $\begin{array}{l}\text { Pharmacological waste } \\
\text { collection }\end{array}$ \\
\hline 15 & Brandão (Brandão, 2020) & $\begin{array}{l}\text { Minimize the number } \\
\text { of routes }\end{array}$ & $\begin{array}{l}\text { Local search } \\
\text { algorithm }\end{array}$ & Transportation network \\
\hline 16 & Zhen et al. (Zhen et al., 2020) & $\begin{array}{l}\text { Minimize the total } \\
\text { travelling and service } \\
\text { time }\end{array}$ & $\begin{array}{l}\text { Hybrid particle } \\
\text { swarm } \\
\text { optimization } \\
\begin{array}{l}\text { algorithm and a } \\
\text { Hybrid genetic } \\
\text { algorithm }\end{array} \\
\end{array}$ & $\begin{array}{l}\text { Practical operations of } \\
\text { online shopping package } \\
\text { delivery }\end{array}$ \\
\hline
\end{tabular}

\section{Heuristic and meta-heuristic methods}

The existing literature presents a large number of solutions for MDVRP through analytical, heuristic and meta-heuristic techniques. The objective of the analytical techniques is to find exact optimal solutions but due to the requirement of generating fast solutions on large scale, this is not met up to the expectation practically. Due to the NP-hardness of the MDVRP, the researchers have started proposing heuristic and meta-heuristic techniques which gives solutions that are computationally tractable.

An integrated Multi-Depot Hub-Location Vehicle Routing model for network planning of parcel service which simultaneously determined the number, location, service areas, routes from demand points to depots and vice versa and the number and locations of hubs and routes of depot-hub and hubhub transports was studied by the authors of (Wasner \& Zäpfel, 2004) in 2011. A generalized hub location and VR model was developed and solved using a hierarchical method embedded in a local search method where heuristics worked successively through various parts of the problem.

An extension of the MDVRP where vehicles may be replenished at inter depots along their route was addressed in (Crevier et al., 2007). The problem was formulated based on a real-life grocery distribution problem using integer programming and solved using a heuristic combining the adaptive memory principle.

Ho et al. (Ho et al., 2008) presents two robust hybrid genetic algorithms for a MDVRP where one of the algorithms used initial solutions generated by a random process and the other utilized an initialization procedure incorporated by The Clarke and Wright saving method and the nearest neighbor heuristic.

The authors of (Mirabi et al., 2010) have developed three hybrid heuristic algorithms which combine elements from constructive heuristic search and improvement techniques that are stochastic 
in order to solve a MDVRP. This is the first application of hybrid heuristics to solve a MDVRP and its success was apparent by the fact that it has outperformed one of the best known existing heuristic.

The MDVRP was studied from a perspective of location routing and periodic routing problems by Prodhon in (Prodhon, 2011) and a hybrid heuristic solution was developed based on an algorithm known as Randomized Extended Clarke and Write Algorithm (RECWA), where periodic VRPs and location routing problems are combined to result in a feasible solution.

(Yu et al., 2011) has explored the MDVRP having a virtual central depot, which makes it resemble a classical VRP.

(Aras et al., 2011) presents an extension of the classical MDVRP based on a realistic problem faced by a firm associated with durable goods industry which aims to collect products from dealers. The authors have formulated two mixed integer linear programming models for this problem and solved using a Tabu Search based heuristic approach.

Customer allocation is a strategy that can be used to solve MDVRP. This approach divides a large scale MDVRP into multiple single depot VRPs which reduces the computational complexity of the MDVRP algorithm. The nearest-depot approach, cluster approach and the border customer approach are various customer allocation strategies that can be employed. Using meta heuristics to solve a MDVRP developed by a customer allocation strategy is realistic and (Tu et al., 2014) proposes a bilevel Voronoi diagram based meta heuristic to solve a large scale MDVRP.

The Vehicle Routing Problem with Pickups and Deliveries was studied in 2005 by Nagy and Salhi (Nagy \& Salhi, 2005). The authors have introduced heuristic algorithms for this problem which can also be used as solutions for MDVRP with positive results.

Another MDVRP related to simultaneous deliveries and pickups was proposed by authors of (J. Li et al., 2015) and solved using a meta-heuristic approach based on an iterated local search. It was observed from the tested computational results that the proposed approach outperforms the previous methods and is better than using large neighbourhood search, particle swarm optimization or ant colony optimization.

Moreover, an integer programming based heuristic model was proposed in (Gulczynski et al., 2011) by Gulczynski et al. with respect to a MDVRP considering split delivery.

A variant of the MDVRP, the min-max Split Delivery MDVRP with Minimum Service Time Requirement (min-max SDMDVRP-MSTR) was solved using a heuristic approach by Wang et al. which operates in the following three stages (X. Wang et al., 2016).

1) Initialize a feasible solution without splits

2) Improve the longest routes by splitting service times

3) Ensure all minimum service time requirements are satisfied

A novel real life problem related to heterogeneous fleet, a Multi-Depot Multi-Period VRP was studied in (Mancini, 2016) by Simona Mancini. The problem was investigated for a heterogeneous fleet comprising of vehicles with different capacities, characteristics and hourly costs through formulation of a mixed integer programming with the objective of minimizing the total delivery cost. An interesting difference observed in comparison to the classical VRPs is that, not every customer may/will be served by all the vehicles or from all the depots (Mancini, 2016). The problem was solved using an Adaptive Large Neighbourhood Search based Matheuristic approach involving variety of destroy operators. The future research in this direction are suggested to be conducted addressing the cases of introduction of customer product compatibilities which makes the situation even more realistic.

In (Afshar-Nadjafi \& Afshar-Nadjafi, 2017), a time-dependent MDVRP is considered with the objective of minimizing the total heterogeneous fleet cost under the assumption that the travel time between locations is dependent on the departure time. The authors have utilized a mixed integer programming model in formulation of the problem and a heuristic process was presented as the solution procedure. It was then evaluated on a large sample of test problems, viz. 180 and have confirmed to result in a satisfying solution.

Hazardous material transportation has caught attention in the recent years due to the intense demand and potential threats to the public. In 2017, (Du et al., 2017) have proposed a fuzzy bilevel programming model for a MDVRP transporting hazardous materials, aimed at minimizing the total expected transportation risk involved in delivery. The optimal solution of the model involved four fuzzy simulation based heuristic algorithms. 
A study addressing a current real life situation was presented in (Zhou et al., 2018) which involved two levels of routing problems. It revolves around a new city logistics problem in the last mile distribution of e-commerce with the objective of minimizing the total distribution cost. Zhou et al. have proposed a hybrid multi population genetic algorithm whose initial part involved an effective heuristic algorithm which generates initial solutions and the proposed method was successfully tested on a large scale real world instance.

The Multi-Depot Green Vehicle Routing Problems (MDGVRP) focuses on reducing the vehicle emissions other than on usual factors such as cost minimization, profit maximization, travel time minimization etc. In 2019, a MDGVRP was developed by (Y. Li et al., 2019) which minimizes revenue, cost, time and emission and solved by application of an improved ant colony optimization algorithm.

Furthermore, (Y. Wang et al., 2019) in the same year was focused on MDGVRP related to a freight distribution. There, a transportation resource sharing strategy was introduced and a bi-objective model was developed to minimize total carbon emission and operating cost. Furthermore, a hybrid heuristic algorithm was also introduced for vehicle routing optimization.

(Jabir et al., 2017) have studied about the MDGVRP focusing on the minimization of the economic and emission costs in a capacitated MDVRP. Integer linear programming models were proposed which could be solved using LINGO solver in small scale instances and using Ant Colony Optimization (ACO) based meta-heuristic in both large and small scale instances. Furthermore, the performance of the ACO based meta-heuristic was improved by integrating with a variable neighbourhood search. This can be regarded as the former study conducted on Capacitated MDGVRPs and the authors suggest future research focusing on manufacturing related emissions and logistics emissions influence on the route design, combining facility planning and routing, production scheduling and routing in integrated decision making of the green VRP and the impact of the emission details on the supply chain decisions such as pricing of the products.

The corresponding models developed can be described as follows (Jabir et al., 2017).

\section{Model 1: Total economic cost reduction model.}

Minimize

$$
\text { Economic cost }=\sum_{v=1}^{V} \sum_{i=1}^{m+n} \sum_{j=1}^{m+n} x_{i j v} l_{i j} C_{v a r}+\sum_{v=1}^{V} \sum_{i=1}^{m} \sum_{j=m+1}^{m+n} x_{i j v} C_{f i x}
$$

Model 2: Total emission cost reduction model.

Minimize

Emission cost $=\sum_{v=1}^{V} \sum_{i=1}^{m+n} \sum_{j=1}^{m+n} l_{i j} P_{\mathrm{CO}_{2}} w_{\mathrm{CO}_{2}} V_{\text {eff }} w_{i j v} w_{p}+\sum_{v=1}^{V} \sum_{i=1}^{m+n} \sum_{j=1}^{m+n} x_{i j v} l_{i j} P_{\mathrm{CO}_{2}} w_{\mathrm{CO}_{2}} V_{\text {eff }} \frac{w_{C u r b}}{k}$

Model 3: Integrated total cost reduction model where the combined influence of emission as well as economic cost on route planning is analyzed.

$$
\begin{aligned}
& \text { Total cost }=\text { Economic cost }+ \text { Emission cost } \\
& =\sum_{v=1}^{V} \sum_{i=1}^{m+n} \sum_{j=1}^{m+n} x_{i j v} l_{i j} C_{v a r}+\sum_{v=1}^{V} \sum_{i=1}^{m} \sum_{j=m+1}^{m+n} x_{i j v} C_{f i x}+ \\
& \sum_{v=1}^{V} \sum_{i=1}^{m+n} \sum_{j=1}^{m+n} l_{i j} P_{\mathrm{CO}_{2}} w_{C O_{2}} V_{e f f} w_{i j v} w_{p}+\sum_{v=1}^{V} \sum_{i=1}^{m+n} \sum_{j=1}^{m+n} x_{i j v} l_{i j} P_{C_{2}} w_{C O_{2}} V_{e f f} \frac{w_{C u r b}}{k}
\end{aligned}
$$

Where,

Decision variables:

$$
\begin{gathered}
x_{i j v}=\left\{\begin{array}{r}
1, \text { if vehicle } v \text { travels from node } i \text { to node } j, i=1, \ldots, n+m, j=1, \ldots, m+n, v=1, \ldots, V \\
0, \text { otherwise }
\end{array}\right. \\
w_{i j v}-\text { the number of units of cargo carried by the vehicle } v \text { from node } i \text { to node } j
\end{gathered}
$$

Indices:
$i, j-$
node indices
$v-$
vehicle indices 


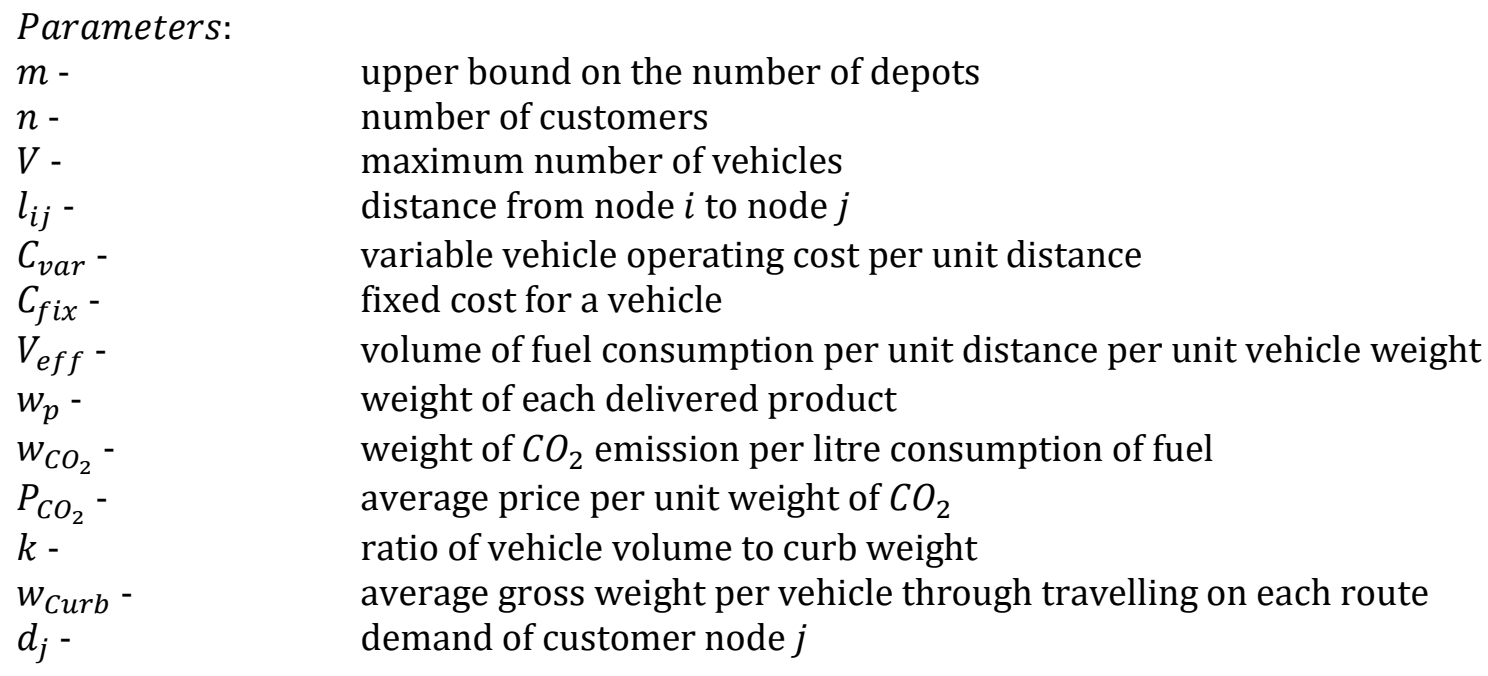

In (Soeanu et al., 2020), the authors presented a cost effective learning-based heuristic technique intricated through an illustrative case study. The solution was developed by keeping track on minimizing the routing and potential costs which might occur due to the risk of vehicle breakdown and cargo delivery failure.

Table 2 presents an overview of the constraints, solution methods and the real-life applications considered in developing the heuristic and meta-heuristic solutions for MDVRP during the last five years.

Table 2: Summary of MDVRPs presenting heuristic and meta-heuristic methods of solution from 2015-2020

\begin{tabular}{|c|c|c|c|c|}
\hline $\mathbf{S} / \mathbf{N}$ & Authors & Constraints considered & Solution technique & Real-life application \\
\hline 1 & $\begin{array}{l}\text { Wasner et al. (Wasner } \\
\text { \& Zäpfel, 2004) }\end{array}$ & $\begin{array}{l}\text { Determination } \\
\text { optimal network }\end{array}$ & $\begin{array}{l}\text { Hierarchical method } \\
\text { embedded in a local search } \\
\text { method }\end{array}$ & $\begin{array}{l}\text { Network planning of parcel } \\
\text { service }\end{array}$ \\
\hline 2 & $\begin{array}{l}\text { Crevier et al. (Crevier } \\
\text { et al., 2007) }\end{array}$ & $\begin{array}{l}\text { Determination of least } \\
\text { cost feasible } \\
\text { rotations }\end{array}$ & $\begin{array}{l}\text { Heuristic combining the } \\
\text { adaptative memory } \\
\text { principle, a tabu } \\
\text { search method and integer } \\
\text { programming }\end{array}$ & Grocery distribution problem \\
\hline 3 & $\begin{array}{l}\text { Mirabi et al. (Mirabi et } \\
\text { al., 2010) }\end{array}$ & $\begin{array}{l}\text { Minimizing delivery } \\
\text { time. }\end{array}$ & $\begin{array}{l}\text { Constructive Heuristic } \\
\text { search and improvement } \\
\text { technique. }\end{array}$ & Transportation network. \\
\hline 4 & $\begin{array}{l}\text { Prodhon (Prodhon, } \\
\text { 2011) }\end{array}$ & $\begin{array}{l}\text { Constraints on } \\
\text { customers to be served } \\
\text { on each day, number of } \\
\text { vehicles, route and total } \\
\text { load of the route. }\end{array}$ & Hybrid heuristic approach. & Transportation network. \\
\hline 5 & $\begin{array}{l}\text { Yu et al. (Yu et al., } \\
2011 \text { ) }\end{array}$ & $\begin{array}{l}\text { Minimizing route costs } \\
\text { that can facilitate } \\
\text { delivery from multiple } \\
\text { depots to a number of } \\
\text { customer locations. }\end{array}$ & $\begin{array}{l}\text { Heuristic algorithm and a } \\
\text { parallel improved ant } \\
\text { colony optimization. }\end{array}$ & Transportation network. \\
\hline 6 & $\begin{array}{l}\text { Aras et al. (Aras et al., } \\
\text { 2011) }\end{array}$ & $\begin{array}{l}\text { Optimize route of a } \\
\text { homogeneous } \\
\text { capacitated vehicles. }\end{array}$ & $\begin{array}{l}\text { Tabu search based heuristic } \\
\text { approach. }\end{array}$ & $\begin{array}{l}\text { Collection of cores from } \\
\text { dealers by firms in durable } \\
\text { goods industry. }\end{array}$ \\
\hline 7 & $\begin{array}{l}\text { Tu et al. (Tu et al., } \\
\text { 2014) }\end{array}$ & $\begin{array}{l}\text { Minimizing the } \\
\text { increment of route } \\
\text { lengths. }\end{array}$ & $\begin{array}{l}\text { Bilevel Voronoi based meta- } \\
\text { heuristic approach }\end{array}$ & Transportation network. \\
\hline 8 & $\begin{array}{l}\text { Nagy and Salhi (Nagy } \\
\text { \& Salhi, 2005) }\end{array}$ & $\begin{array}{l}\text { Meeting pickups and } \\
\text { delivery simultaneously. }\end{array}$ & Heuristic approach. & Transportation network. \\
\hline 9 & $\begin{array}{l}\text { Li et al. (J. Li et al., } \\
\text { 2015) }\end{array}$ & $\begin{array}{l}\text { Meeting pickups and } \\
\text { delivery simultaneously. }\end{array}$ & $\begin{array}{l}\text { Meta-Heuristic approach } \\
\text { based on iterated local } \\
\text { search. }\end{array}$ & Transportation network. \\
\hline
\end{tabular}




\begin{tabular}{|c|c|c|c|c|}
\hline 10 & $\begin{array}{lll}\text { Gulczynski } & \text { et } & \text { al. } \\
\text { (Gulczynski } & \text { et } & \text { al., } \\
2011) & & \end{array}$ & & Heuristic approach. & Transportation network. \\
\hline 11 & $\begin{array}{l}\text { Wang et al. (Y. Wang et } \\
\text { al., 2019) }\end{array}$ & $\begin{array}{l}\text { Minimizing the duration } \\
\text { of the longest route. }\end{array}$ & Heuristic approach. & Transportation network. \\
\hline 12 & $\begin{array}{l}\text { Mancini (Mancini, } \\
\text { 2016) }\end{array}$ & $\begin{array}{l}\text { Minimizing the total } \\
\text { delivery cost. }\end{array}$ & $\begin{array}{l}\text { Adaptive } \quad \text { large } \\
\text { neighbourhood search } \\
\text { based Meta-Heuristic. }\end{array}$ & Transportation network. \\
\hline 13 & $\begin{array}{l}\text { Nadjafi et al. (Afshar- } \\
\text { Nadjafi \& Afshar- } \\
\text { Nadjafi, 2017) }\end{array}$ & $\begin{array}{l}\text { Minimizing the total } \\
\text { heterogeneous fleet cost } \\
\text { and Hard time window } \\
\text { constraints for the } \\
\text { customers and limitation } \\
\text { on maximum number of } \\
\text { vehicles. }\end{array}$ & $\begin{array}{l}\text { Constructive } \quad \text { Heuristic } \\
\text { approach. }\end{array}$ & Transportation network. \\
\hline 14 & $\begin{array}{l}\text { Du et al. (Du et al., } \\
2017 \text { ) }\end{array}$ & $\begin{array}{l}\text { Minimizing total } \\
\text { expected transportation } \\
\text { risk. }\end{array}$ & $\begin{array}{l}\text { Fuzzy simulation based } \\
\text { heuristic approach. }\end{array}$ & $\begin{array}{l}\text { Serving customers with a fleet } \\
\text { of vehicles in a pregiven road } \\
\text { network. }\end{array}$ \\
\hline 15 & $\begin{array}{l}\text { Zhou et al. (Zhou et al., } \\
\text { 2018) }\end{array}$ & $\begin{array}{l}\text { Minimizing the total } \\
\text { distribution cost. }\end{array}$ & Heuristic approach. & $\begin{array}{l}\text { Last minute distributions in e- } \\
\text { commerce. }\end{array}$ \\
\hline 16 & $\begin{array}{l}\text { Li et al. (Y. Li et al., } \\
\text { 2019) }\end{array}$ & $\begin{array}{l}\text { Minimizing revenue, } \\
\text { cost, time and emission. }\end{array}$ & $\begin{array}{l}\text { Improved ant colony } \\
\text { algorithm. }\end{array}$ & Transportation network. \\
\hline 17 & $\begin{array}{l}\text { Wang et al. (Y. Wang et } \\
\text { al., 2019) }\end{array}$ & $\begin{array}{l}\text { Minimizing total carbon } \\
\text { emission and operating } \\
\text { cost. }\end{array}$ & Hybrid heuristic algorithm. & Freight distribution. \\
\hline 18 & $\begin{array}{l}\text { Jabir et al. (Jabir et al., } \\
\text { 2017) }\end{array}$ & $\begin{array}{l}\text { Minimizing economic } \\
\text { and emission costs. }\end{array}$ & $\begin{array}{l}\text { LINGO solver and ant colony } \\
\text { optimization based meta- } \\
\text { heuristic. }\end{array}$ & Transportation network. \\
\hline 19 & $\begin{array}{l}\text { Soeanu et al. (Soeanu } \\
\text { et al., 2020) }\end{array}$ & $\begin{array}{l}\text { Minimizing the routing } \\
\text { and potential costs. }\end{array}$ & Heuristic approach. & Transportation network. \\
\hline
\end{tabular}

\section{Conclusion}

The objective of the MDVRP problem is to find routes for vehicles to service all the customers at a minimal cost in terms of number of routes and total travel distance, without violating the capacity and travel time constraints of the vehicles. MDVRP is much more beneficial than VRP because here we have more than one number of depots to serve customers which is done in lesser time as compare to VRP; if time reduces then cost on delivery is also reduced. Travelling salesman problem which is a VRP can be solved by many ways and much research has been done on solving VRP by various techniques or methods. Since MDVRP is basically to reduce distance i.e. cost so effective techniques such as heuristic methods in swarm intelligence should be taken instead of exact methods like branch and bound method or computational complexities which are not suitable to obtain optimal solutions. Future work includes the use of heuristic search methods which will give optimal solutions to the MDVRP.

\section{Citation information}

Jayarathna, N., Lanel, J., \& Juman, Z. A. M. S. (2020). Five years of multi-depot vehicle routing problems. Journal of Sustainable Development of Transport and Logistics, 5(2), 109-123. doi:10.14254/jsdtl.2020.5-2.10.

\section{References}

Afshar-Nadjafi, B., \& Afshar-Nadjafi, A. (2017). A constructive heuristic for time-dependent multi-depot vehicle routing problem with time-windows and heterogeneous fleet. Journal of King Saud University - Engineering Sciences, 29(1), 29-34. https://doi.org/10.1016/j.jksues.2014.04.007

Alinaghian, M., \& Shokouhi, N. (2018). Multi-depot multi-compartment vehicle routing problem, solved by a hybrid adaptive large neighborhood search. Omega, 76, 85-99. https://doi.org/10.1016/j.omega.2017.05.002 
Aras, N., Aksen, D., \& Tuğrul Tekin, M. (2011). Selective multi-depot vehicle routing problem with pricing. Transportation Research Part C: Emerging Technologies, 19(5), 866-884. https://doi.org/10.1016/j.trc.2010.08.003

Brandão, J. (2020). A memory-based iterated local search algorithm for the multi-depot open vehicle routing problem. European Journal of Operational Research, 284(2), 559-571. https://doi.org/10.1016/j.ejor.2020.01.008

Contardo, C., \& Martinelli, R. (2014). A new exact algorithm for the multi-depot vehicle routing problem under capacity and route length constraints. Discrete Optimization, 12, 129-146. https://doi.org/10.1016/j.disopt.2014.03.001

Crevier, B., Cordeau, J.-F., \& Laporte, G. (2007). The multi-depot vehicle routing problem with interdepot routes. European Journal of Operational Research, 176(2), 756-773. https://doi.org/10.1016/j.ejor.2005.08.015

de Oliveira, F. B., Enayatifar, R., Sadaei, H. J., Guimarães, F. G., \& Potvin, J.-Y. (2016). A cooperative coevolutionary algorithm for the Multi-Depot Vehicle Routing Problem. Expert Systems with Applications, 43, 117-130. https://doi.org/10.1016/j.eswa.2015.08.030

Du, J., Li, X., Yu, L., Dan, R., \& Zhou, J. (2017). Multi-depot vehicle routing problem for hazardous materials transportation: A fuzzy bilevel programming. Information Sciences, 399, 201-218. https://doi.org/10.1016/j.ins.2017.02.011

Ganepola, D. D., Jayarathna, D. G. N. D., \& Madhushani, G. (2018). An intelligent cost optimized central warehouse and redistribution root plan with truck allocation system in Colombo region for Lion Brewery Ceylon PLC.

Gulczynski, D., Golden, B., \& Wasil, E. (2011). The multi-depot split delivery vehicle routing problem: An integer programming-based heuristic, new test problems, and computational results. Computers \& Industrial Engineering, 61(3), 794-804. https://doi.org/10.1016/j.cie.2011.05.012

Ho, W., Ho, G. T. S., Ji, P., \& Lau, H. C. W. (2008). A hybrid genetic algorithm for the multi-depot vehicle routing problem. Engineering Applications of Artificial Intelligence, 21(4), 548-557. https://doi.org/10.1016/j.engappai.2007.06.001

Jabir, E., Panicker, V. V., \& Sridharan, R. (2017). Design and development of a hybrid ant colony-variable neighbourhood search algorithm for a multi-depot green vehicle routing problem. Transportation Research Part D: Transport and Environment, 57, 422-457. https://doi.org/10.1016/j.trd.2017.09.003

Jayarathna, D. G. N. D., Lanel, G. H. J., \& Juman, Z. (2019). A Contemporary Recapitulation of Major Findings on Vehicle Routing Problems: Models and Methodologies. International Journal of Recent Technology and Engineering (IJRTE) Volume 8, 8(2S4), 581-585.

Kachitvichyanukul, V., Sombuntham, P., \& Kunnapapdeelert, S. (2015). Two solution representations for solving multi-depot vehicle routing problem with multiple pickup and delivery requests via PSO. Computers \& Industrial Engineering, 89, 125-136. https://doi.org/10.1016/j.cie.2015.04.011

Kramer, R., Cordeau, J. F., \& Iori, M. (2019). Rich vehicle routing with auxiliary depots and anticipated deliveries: An application to pharmaceutical distribution. Transportation Research Part E: Logistics and Transportation Review, 129, 162-174. https://doi.org/10.1016/j.tre.2019.07.012

Li, J., Pardalos, P. M., Sun, H., Pei, J., \& Zhang, Y. (2015). Iterated local search embedded adaptive neighborhood selection approach for the multi-depot vehicle routing problem with simultaneous deliveries and pickups. Expert Systems with Applications, 42(7), 3551-3561. https://doi.org/10.1016/j.eswa.2014.12.004

Li, J., Wang, R., Li, T., Lu, Z., \& Pardalos, P. M. (2018). Benefit analysis of shared depot resources for multidepot vehicle routing problem with fuel consumption. Transportation Research Part D: Transport and Environment, 59, 417-432. https://doi.org/10.1016/j.trd.2018.01.026 
Li, Y., Soleimani, H., \& Zohal, M. (2019). An improved ant colony optimization algorithm for the multidepot green vehicle routing problem with multiple objectives. Journal of Cleaner Production, 227, 1161-1172. https://doi.org/10.1016/j.jclepro.2019.03.185

Mancini, S. (2016). A real-life Multi Depot Multi Period Vehicle Routing Problem with a Heterogeneous Fleet: Formulation and Adaptive Large Neighborhood Search based Matheuristic. Transportation Research Part C: Emerging Technologies, 70, 100-112. https://doi.org/10.1016/j.trc.2015.06.016

Mirabi, M., Fatemi Ghomi, S. M. T., \& Jolai, F. (2010). Efficient stochastic hybrid heuristics for the multidepot vehicle routing problem. Robotics and Computer-Integrated Manufacturing, 26(6), 564-569. https://doi.org/10.1016/j.rcim.2010.06.023

Modeling of an Optimal Outbound Logistics System (A Contemporary Review Study on effects of Vehicle Routing, Facility Location and Locational Routing Problems). (n.d.). Retrieved January 20, 2020, from http://www.ijhssi.org/papers/vol8(10)/Series-2/C0810020830.pdf

Montoya-Torres, J. R., López Franco, J., Nieto Isaza, S., Felizzola Jiménez, H., \& Herazo-Padilla, N. (2015). A literature review on the vehicle routing problem with multiple depots. Computers \& Industrial Engineering, 79, 115-129. https://doi.org/10.1016/j.cie.2014.10.029

Nagy, G., \& Salhi, S. (2005). Heuristic algorithms for single and multiple depot vehicle routing problems with pickups and deliveries. European Journal of Operational Research, 162(1), 126-141. https://doi.org/10.1016/j.ejor.2002.11.003

Osaba, E., Yang, X.-S., Diaz, F., Onieva, E., Masegosa, A. D., \& Perallos, A. (2017). A Discrete Firefly Algorithm to Solve a Rich Vehicle Routing Problem Modelling a Newspaper Distribution System with Recycling Policy. Soft Computing, 21(18), 5295-5308. https://doi.org/10.1007/s00500-0162114-1

Osaba, Eneko, Yang, X.-S., Fister, I., Del Ser, J., Lopez-Garcia, P., \& Vazquez-Pardavila, A. J. (2019). A Discrete and Improved Bat Algorithm for solving a medical goods distribution problem with pharmacological waste collection. Swarm and Evolutionary Computation, 44, 273-286. https://doi.org/10.1016/j.swevo.2018.04.001

Pardalos, P., \& Coleman, T. (Eds.). (2009). Lectures on Global Optimization. American Mathematical Society. https://doi.org/10.1090/fic/055

Prodhon, C. (2011). A hybrid evolutionary algorithm for the periodic location-routing problem. European Journal of Operational Research, 210(2), 204-212.

Ropke, S., \& Pisinger, D. (2006). An Adaptive Large Neighborhood Search Heuristic for the Pickup and Delivery Problem with Time Windows. Transportation Science, 40(4), 455-472. https://doi.org/10.1287/trsc.1050.0135

Salhi, S., Imran, A., \& Wassan, N. A. (2014). The multi-depot vehicle routing problem with heterogeneous vehicle fleet: Formulation and a variable neighborhood search implementation. Computers \& Operations Research, 52, 315-325. https://doi.org/10.1016/j.cor.2013.05.011

Seyyedhasani, H., \& Dvorak, J. S. (2018). Dynamic rerouting of a fleet of vehicles in agricultural operations through a Dynamic Multiple Depot Vehicle Routing Problem representation. Biosystems Engineering, 171, 63-77. https://doi.org/10.1016/j.biosystemseng.2018.04.003

Soeanu, A., Ray, S., Berger, J., Boukhtouta, A., \& Debbabi, M. (2020). Multi-depot vehicle routing problem with risk mitigation: Model and solution algorithm. Expert Systems with Applications, 145, 113099. https://doi.org/10.1016/j.eswa.2019.113099

Soto, M., Sevaux, M., Rossi, A., \& Reinholz, A. (2017). Multiple neighborhood search, tabu search and ejection chains for the multi-depot open vehicle routing problem. Computers \& Industrial Engineering, 107, 211-222. https://doi.org/10.1016/j.cie.2017.03.022

Tohidifard, M., Tavakkoli-Moghaddam, R., Navazi, F., \& Partovi, M. (2018). A Multi-Depot Home Care Routing Problem with Time Windows and Fuzzy Demands Solving by Particle Swarm Optimization and Genetic Algorithm. https://doi.org/10.1016/j.ifacol.2018.08.318 
Tu, W., Fang, Z., Li, Q., Shaw, S.-L., \& Chen, B. (2014). A bi-level Voronoi diagram-based metaheuristic for a large-scale multi-depot vehicle routing problem. Transportation Research Part E: Logistics and Transportation Review, 61, 84-97. https://doi.org/10.1016/j.tre.2013.11.003

Wang, X., Golden, B., Wasil, E., \& Zhang, R. (2016). The min-max split delivery multi-depot vehicle routing problem with minimum service time requirement. Computers \& Operations Research, 71, 110-126. https://doi.org/10.1016/j.cor.2016.01.008

Wang, Y., Assogba, K., Fan, J., Xu, M., Liu, Y., \& Wang, H. (2019). Multi-depot green vehicle routing problem with shared transportation resource: Integration of time-dependent speed and piecewise penalty cost. Journal of Cleaner Production, 232, 12-29. https://doi.org/10.1016/j.jclepro.2019.05.344

Wasner, M., \& Zäpfel, G. (2004). An integrated multi-depot hub-location vehicle routing model for network planning of parcel service. International Journal of Production Economics, 90(3), 403-419. https://doi.org/10.1016/j.ijpe.2003.12.002

Yu, B., Yang, Z.-Z., \& Xie, J.-X. (2011). A parallel improved ant colony optimization for multi-depot vehicle routing problem. Journal of the Operational Research Society, 62(1), 183-188. https://doi.org/10.1057/jors.2009.161

Yücenur, G. N., \& Demirel, N. Ç. (2011). A new geometric shape-based genetic clustering algorithm for the multi-depot vehicle routing problem. Expert Systems with Applications, 38(9), 11859-11865. https://doi.org/10.1016/j.eswa.2011.03.077

Zhen, L., Ma, C., Wang, K., Xiao, L., \& Zhang, W. (2020). Multi-depot multi-trip vehicle routing problem with time windows and release dates. Transportation Research Part E: Logistics and Transportation Review, 135, 101866. https://doi.org/10.1016/j.tre.2020.101866

Zhou, L., Baldacci, R., Vigo, D., \& Wang, X. (2018). A Multi-Depot Two-Echelon Vehicle Routing Problem with Delivery Options Arising in the Last Mile Distribution. European Journal of Operational Research, 265(2), 765-778. https://doi.org/10.1016/j.ejor.2017.08.011

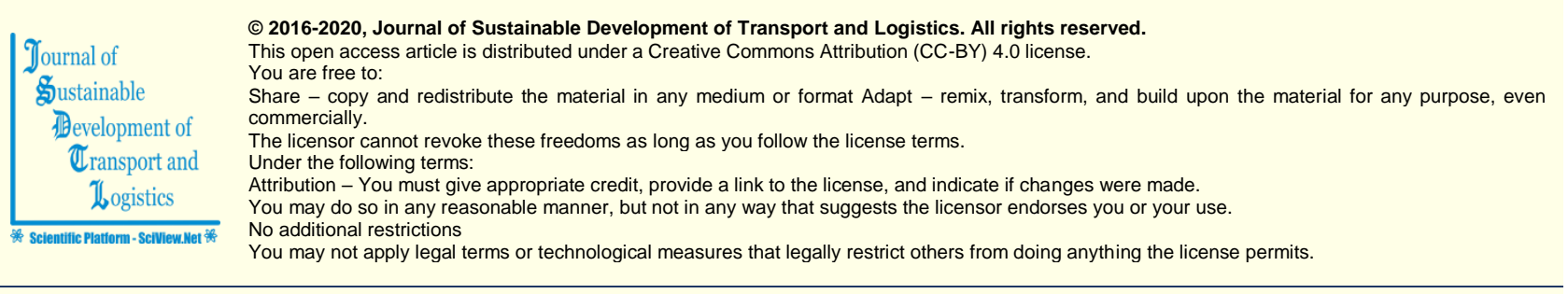

Journal of Sustainable Development of Transport and Logistics (ISSN: 2520-2979) is published by Scientific Publishing House "CSR",

Poland, EU and Scientific Publishing House "SciView", Poland, EU

Publishing with JSDTL ensures:

- Immediate, universal access to your article on publication

- High visibility and discoverability via the JSDTL website

- Rapid publication

- Guaranteed legacy preservation of your article

- Discounts and waivers for authors in developing regions

Submit your manuscript to a JSDTL at https://jsdtl.sciview.net/ or submit.jsdt|@sciview.net 